\title{
ENKRIPSI DATA MENGGUNAKAN ADVANCED ENCRYPTION STANDARD 256
}

\author{
Yudi Wiharto ${ }^{1}$, Ari Irawan ${ }^{2}$ \\ ${ }^{1}$ Program Studi Teknik Informatika, Universitas Budi Luhur, Jakarta, Indonesia \\ ${ }^{2}$ Proram Studi Sistem Informasi, Universitas Tanri Abeng, Jakarta, Indonesia \\ ${ }^{1}$ visited.mymail@gmail.com, ${ }^{2}$ ari_irawan@tau.ac.id
}

\begin{abstract}
Cryptography is important in securing data and information. Confidential, important information may not be publicly or otherwise protected. It is not impossible for anyone to see, damage, steal or misuse important data from an agency or company through a computer network. The solution is with cryptography or a method of data security that can maintain the confidentiality and authenticity of a data or information. This method is intended for confidential information when sent through network access, such as LAN or internet, cannot be utilized by unauthorized parties. Cryptography supports the aspect of information security, namely protection of confidentiality. Therefore the need to maintain the confidentiality of data and information is a cryptographic application. The process in the form of encryption and decryption used by the user to secure the data without changing the contents of the data. This application has a 32-character key but in its use is made into 2 keys, namely public and private key where the public key is the key filled by the user in accordance with the desire, while the private key is the default key entered by the application at random to meet the length of 32 characters. The AES algorithm used is the AES256 algorithm where this algorithm uses the principle with the number of rounds by key.
\end{abstract}

Keywords: Cryptography, AES 256, Encryption, Decryption, Algorithm.

\begin{abstract}
ABSTRAK
Kriptografi penting dalam mengamankan data dan informasi. Informasi rahasia dan penting tidak boleh dilindungi secara publik atau sebaliknya. Bukan tidak mungkin bagi siapa pun untuk melihat, merusak, mencuri atau menyalahgunakan data penting dari agensi atau perusahaan melalui jaringan komputer. Solusinya adalah dengan kriptografi atau metode keamanan data yang dapat menjaga kerahasiaan dan keaslian data atau informasi. Metode ini ditujukan untuk informasi rahasia ketika dikirim melalui akses jaringan, seperti LAN atau internet, tidak dapat dimanfaatkan oleh pihak yang tidak berwenang. Kriptografi mendukung aspek keamanan informasi, yaitu perlindungan kerahasiaan. Oleh karena itu kebutuhan untuk menjaga kerahasiaan data dan informasi adalah aplikasi cryptographic. Prosesnya berupa enkripsi dan dekripsi yang digunakan oleh pengguna untuk mengamankan data tanpa mengubah isi data. Aplikasi ini memiliki kunci 32 karakter tetapi dalam penggunaannya dibuat menjadi 2 kunci, yaitu kunci publik dan privat di mana kunci publik adalah kunci yang diisi oleh pengguna sesuai dengan keinginan, sedangkan kunci privat adalah kunci default yang dimasukkan oleh aplikasi secara acak untuk memenuhi panjang 32 karakter. Algoritma AES yang digunakan adalah algoritma AES256 di mana algoritma ini menggunakan prinsip dengan jumlah putaran berdasarkan kunci.
\end{abstract}

Kata Kunci: Kriptografi, AES 256, Enkripsi, Dekripsi, Algoritma. 


\section{PENDAHULUAN}

Teknologi komputer pada saat ini telah mengalami perkembangan yang sangat pesat, hingga merambah ke segala aspek menyangkut segala kebutuhan dalam pekerjaan manusia. Komputer membutuhkan suatu keamanan dalam penyimpanan data atau informasi adalah hal yang sangat penting dan tidak bisa diabaikan begitu saja. Semakin tinggi tingkatan teknologi komputer, maka akan semakin tinggi pula tingkat ancaman yang akan mengancam keamanan data didalam komputer. Kerahasiaan suatu file yang tersimpan pada komputer harus diberikan pengamanan dan sudah menjadi persyaratan mutlak yang sangat diperlukan untuk melindungi file tersebut terhadap berbagai ancaman seperti dapat dengan mudah seseorang melihat, merusak, mencuri ataupun menyalahgunakan data atau informasi penting dari suatu instansi atau perusahaan melalui jaringan komputer. Kriptografi bertujuan agar data atau informasi tidak dapat dibaca oleh orang yang tidak berhak. Algoritma AES adalah blok chipertext simetrik yang dapat mengenkripsi (encipher) dan dekripsi (decipher) informasi.

Dalam kriptografi ada istilah yang disebut dengan enkripsi (encryption) yaitu proses penyamaran data dari plaintext (data asli) menjadi chiperterxt (data tersandi) dan deskripsi (decryption) yaitu proses pemgembalian chipertext menjadi plaintext kembali.

\section{METODE PENELITIAN}

Untuk menyelesaikan penelitian ini diperlukan pengumpulan data yang berhubungan dengan masalah yang dibahas. Tujuannya sebagai sumber landasan pembahasan dan pembuatan rancangan sistem. Adapun metode penelitian yang digunakan dalam mengumpulkan data atau materi penulisan adalah dengan cara:

\subsection{Pengamatan (observasi)}

Pengamatan atau observasi merupakan salah satu teknik pengumpulan data/fakta yang cukup efektif untuk mempelajari suatu sistem. Pengamatan langsung ini dilakukan untuk mengetahui proses-proses yang sedang berjalan serta membuat keputusan yang menyangkut lingkungan fisiknya pada suatu kegiatan yang sedang berjalan.

2.2 Wawancara (interview)

Wawancara dilakukan untuk mendapatkan data dan informasi dalam bentuk tanya jawab kepada orang yang terlibat secara langsung yang merupakan obyek penelitian.

2.3 Studi Pustaka

Metode ini menggunakan dokumen sebagai sumber bacaan, baik buku-buku ilmiah maupun jurnal, terutama yang erat hubungannya dengan masalah yang di bahas dalam penelitian ini.

\section{HASIL DAN PEMBAHASAN}

Untuk mengimplementasikan enkripsi soal-soal tersebut diperlukan algoritma enkripsi agar soal-soal tersebut bisa di enkrip dan dikembalikan seperti semula atau dekrip tanpa mengalami perubahan. Dengan adanya aplikasi ini diharapkan isi dari soal-soal tersebut dapat disimpan dengan aman tanpa adanya permasalahan.

\subsection{Kebutuhan Sistem}

Pada dasarnya komputer merupakan sebuah sistem yang terdiri dari beberapa komponen yang saling berhubungan dan menghasilkan input, proses, output dan storage. Dengan kata lain komputer memerlukan beberapa komponen dan fungsi perangkat keras yang mendukung proses komputerisasi.

Spesifikasi sistem yang akan dibangun pada aplikasi ini adalah sebagai berikut :

a) Aplikasi harus dapat mendeteksi user yang akan login.

b) Aplikasi mampu mengacak informasi dengan cara mengenkripsi data dan mengembalikannya atau mendekripsikan data terebut seperti semula tanpa adanya perubahan dari data tersebut.

c) Proses enkripsi dan dekripsi harus dilakukan dengan cepat. 


\subsection{Skema Proses Sistem Aplikasi}

Tahapan-tahapan yang terjadi dalam skema proses aplikasi ini adalah sebagai berikut:

\subsubsection{Skema Proses Enkripsi}

Enkripsi merupakan proses pengacakan sebuah informasi atau data pada suatu aplikasi dengan menggunakan algoritma enkripsi, aplikasi yang kami buat menggunakan algoritma AES 256 yang menggunakan satu kunci.

Adapun langkah-langkah pada proses enkripsi simetris ini dapat diuraikan sebagai berikut:

(1) Menginputkan data atau informasi yang ingin dikunci.

(2) Menginputkan bit dengan bilangan angka yang digunakan sebagai kunci rahasia algoritma simetris.

(3) Melakukan proses enkripsi dengan algoritma AES 256 dan melakukan upload ke dalan server lokal.

(4) Menghasilkan output berupa file chiper. Dapat dilihat pada gambar 1.

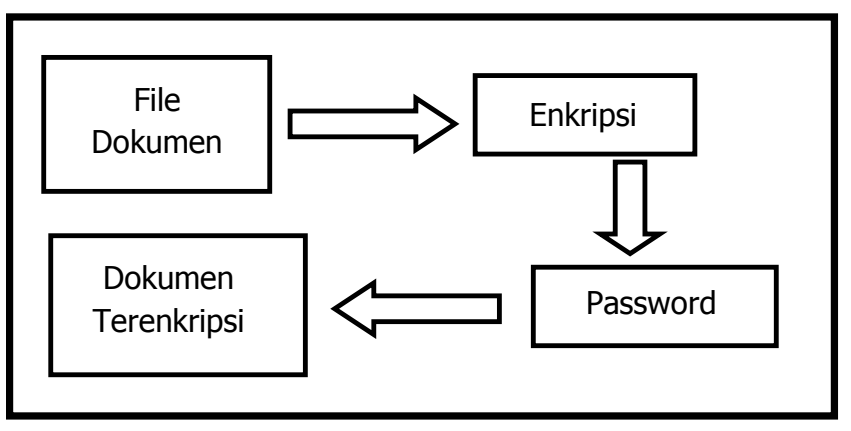

Gambar 1. Proses Enkripsi

\subsubsection{Skema Proses Dekripsi}

Dekripsi merupakan proses pengembalian atau pemulihan sebuah informasi atau data yang telah dienkripsi pada aplikasi ini, dengan menggunakan algoritma AES 256. Proses ini adalah dimana informasi atau data acak (chiper) yang terenkripsi menjadi data asli (plain), dengan algoritma simetris. Adapun langkah-langkah pada proses dekripsi ini dapat diuraikan sebagai berikut:

1. File chiper di download dari server lokal.

2. File chiper didekripsi.

3. Mendekrip file tersebut dengan kunci

4. Menghasilkan output berupa file informasi atau data yang utuh dan dapat dibaca seperti awal. Dapat dilihat pada gambar 2.

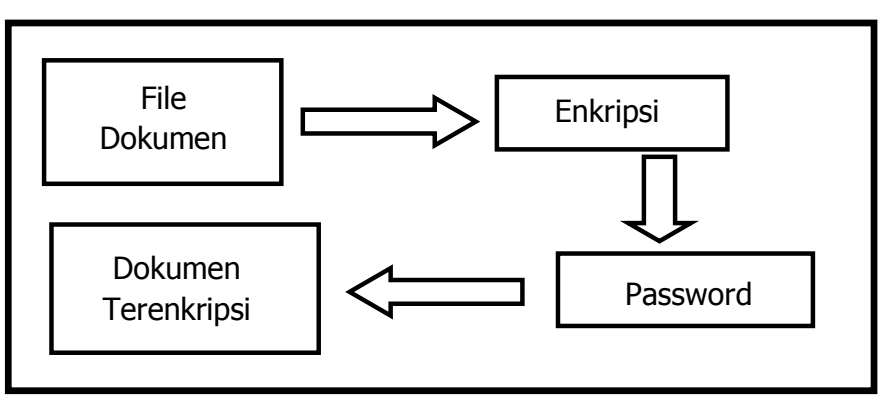

Gambar 2. Proses Dekripsi 


\subsubsection{Algoritma Enkripsi}

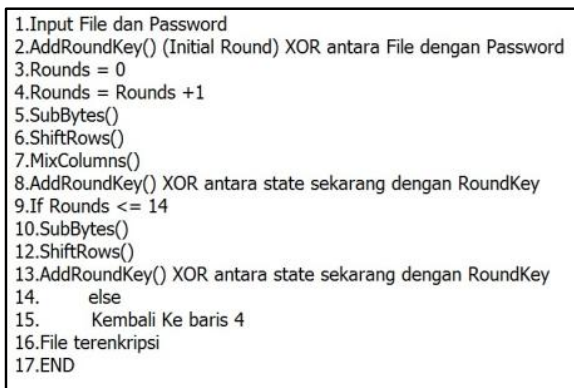

Gambar 3. Algoritma Enkripsi

\subsubsection{Algoritma Dekripsi}

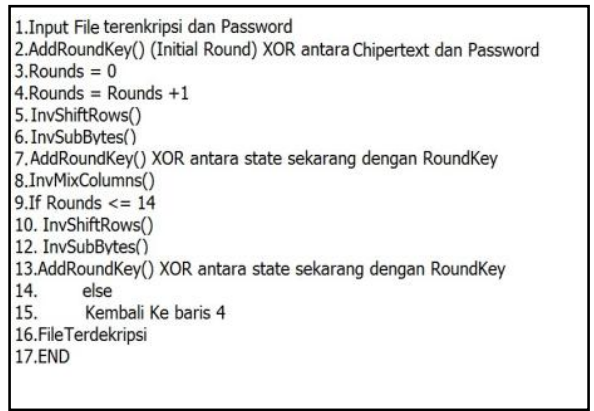

Gambar 4. Algoritma Dekripsi

\subsubsection{Diagram Alir (FlowChart)}

Flowchart merupakan diagram yang menunjukkan bagaimana cara kerja dari sebuah aplikasi untuk masuk pada program pada saat pertama kali dijalankan. Sesuai dengan rancangan layar, maka flowchart yang akan dibuat terdiri dari proses - proses sebagai berikut :
1) Enkripsi
ini menjelaskan bagaimana proses enkripsi, mulai dari proses memilih data yang akan enkripsi, memberikan password. Flowchart dapat dilihat pada gambar 5.

\section{2) Dekripsi}
ini menjelaskan bagaimana proses dekripsi, mulai dari proses memilih data yang akan dekripsi, memberlikan password. Flowchart dapat dilihat pada gambar 6.

\subsection{Data Masukan}

Data masukan yang dimaksud tersebut ialah file atau dokumen yang dapat dienkripsi dengan aplikasi ini. Beberapa dokumen yang dapat dienkripsi adalah dokumen-dokumen yang berekstensi .doc, .docx, .xls, .xlsx, .pdf, .ppt, .pptx. Untuk ukuran data diatas $15 \mathrm{Mb}$ proses pengenkripsian berjalan dengan lambat karena aplikasi ini tidak menggunakan algoritma tambahan seperti algoritma kompresi.

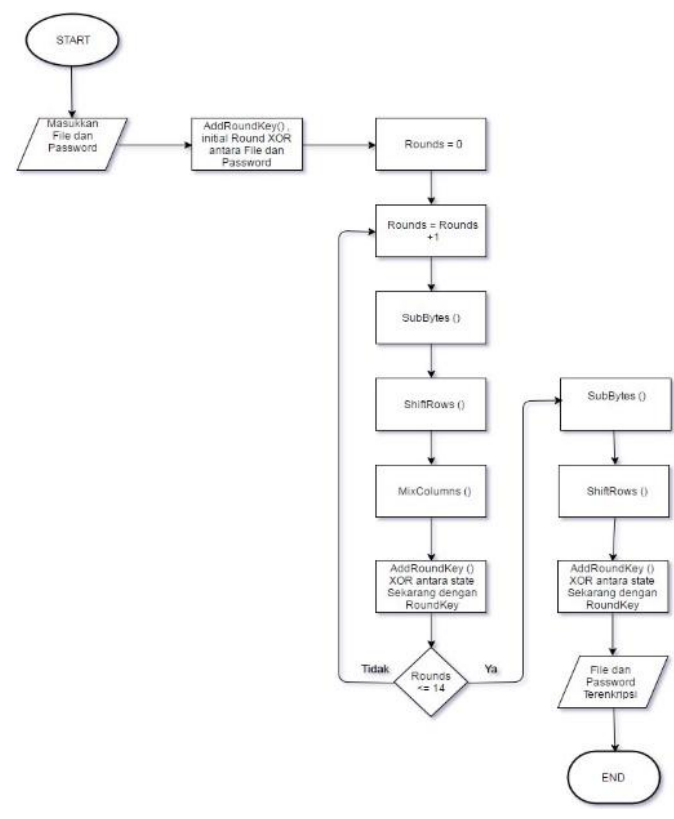

Gamber 5. Flowchart Enkripsi

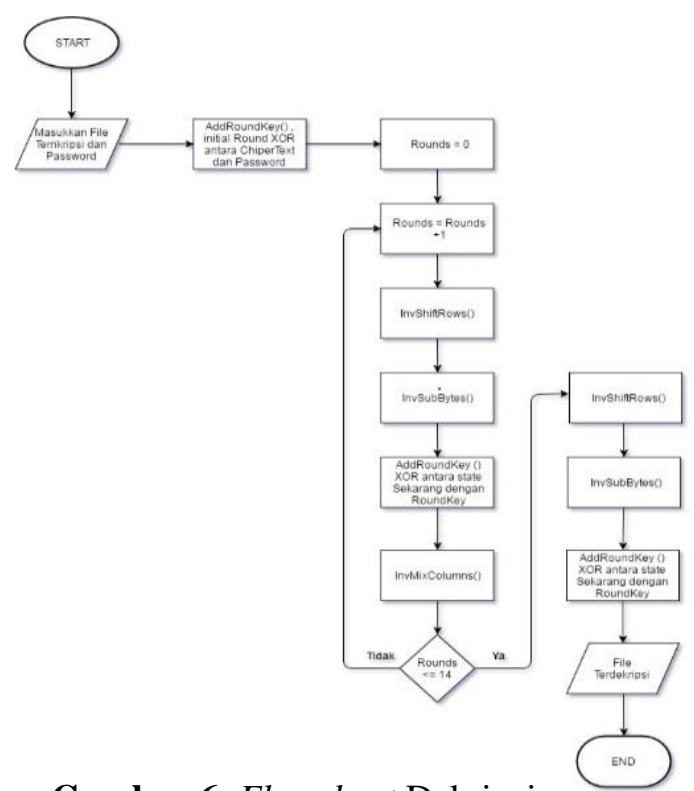

Gambar 6. Flowchart Dekripsi 


\subsection{Langkah Pengujian}

Pada form enkripsi ini terdapat 2 (dua) field yang dapat diisi yaitu field untuk memilih file dan untuk memasukkan password. Jika pengguna ingin melakukan enkripsi maka pengguna harus menekan tombol choose file yang ada pada sisi kanan form. Setelah itu pengguna harus memilih file apa yang akan dienkripsi. Setelah file dipilih, pengguna harus memasukkan password untuk menjaga keamanan dari file yang dienkripsi. Password ini selain digunakan untuk menjaga keamanan file, juga digunakan untuk melakukan dekripsi pada file yang sama.

Setelah memasukkan password, pengguna harus menekan tombol enkripsi. Jika enkripsi berhasil maka akan muncul dialog "proses berhasil" setelah itu muncul popup browse untuk memilih direktori penyimpanan password. Password tersebut disimpan dalam bentuk text, jadi password tidak sembarangan disimpan didalam suatu folder. Jika password yang dimasukkan hilang atau lupa, maka pengguna dapat melihat password yang telah disimpan dan password tersebut dapat disebarkan kepada siswa pada saat ujian dimulai untuk melakukan proses dekripsi terhadap file tersebut. Jika file gagal dienkripsi maka akan muncul dialog "proses gagal". Tampilan form menu Enkripsi dapat dilihat pada gambar 7.

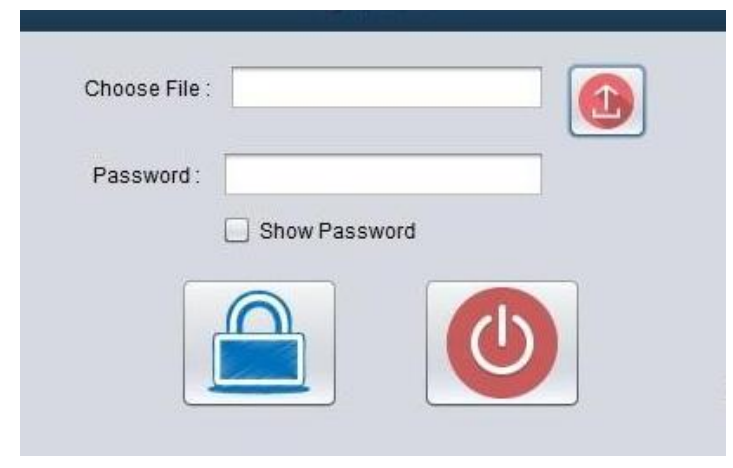

\section{Gambar 7: Tampilan Form Enkripsi}

Pada form dekripsi berikut ini terdapat 2 (dua) field yang dapat diisi yaitu field untuk memilih file dan untuk memasukkan password. Jika pengguna ingin melakukan proses dekripsi, maka pengguna harus menekan tombol choose file yang ada pada sisi kanan form. Setelah itu pengguna harus memilih file apa yang akan didekkripsi. Setelah file dipilih pengguna harus menginputkan password yang sama pada saat file tersebut dienkripsi. Jika dekripsi berhasil maka akan muncul dialog "proses berhasil". Jika file gagal dienkripsi maka akan muncul dialog "proses gagal". Tampilan form dekripsi dapat dilihat pada gambar 8.

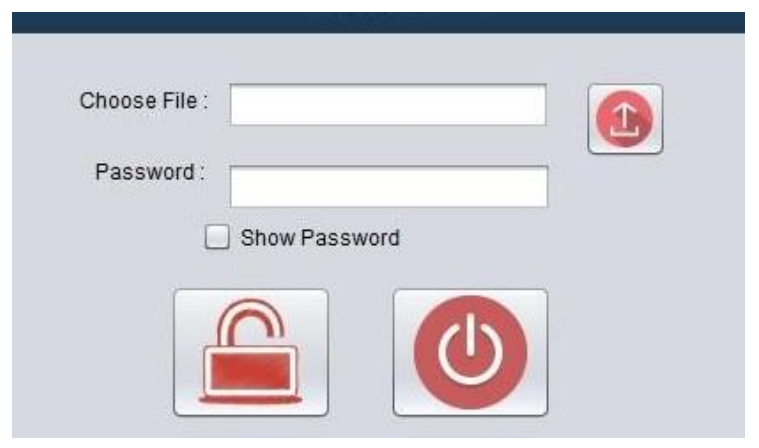

Gambar 8: Tampilan Form Dekripsi

Perbandingan dokumen ini adalah perbandingan dari beberapa dokumen atau file yang sudah terenkripsi dan yang belum terenkripsi. Pertama, file asli (contoh menggunakan file .doc, atau .docx) yang akan dienkripsi terlihat pada gambar 9 . 


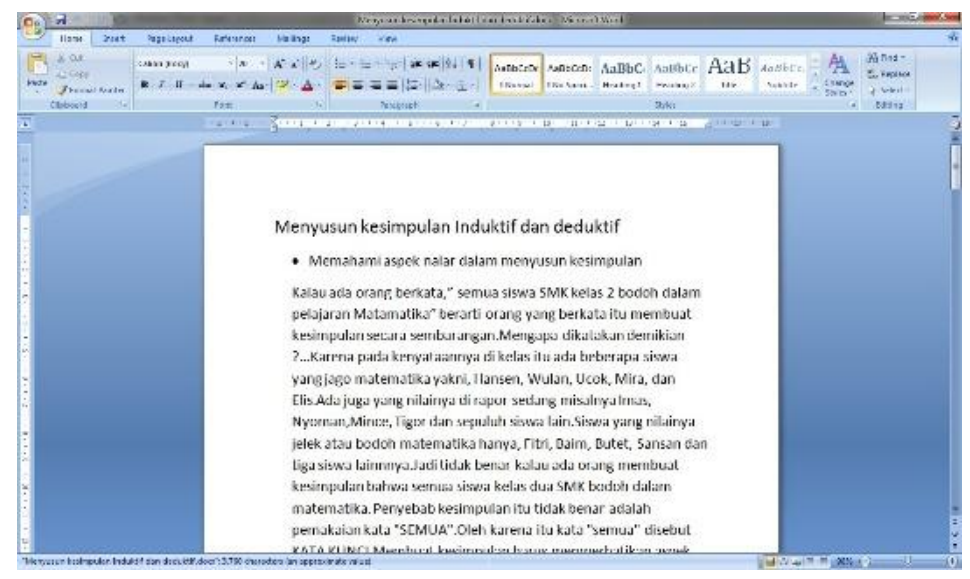

Gambar 9: File berekstensi .doc atau .docx Asli

File tersebut dapat dilihat karena belum terenkripsi, apabila file tersebut sudah terenkripsi maka tidak dapat dibuka lagi. File yang sudah terenkripsi dapat dilihat pada gambar 10.

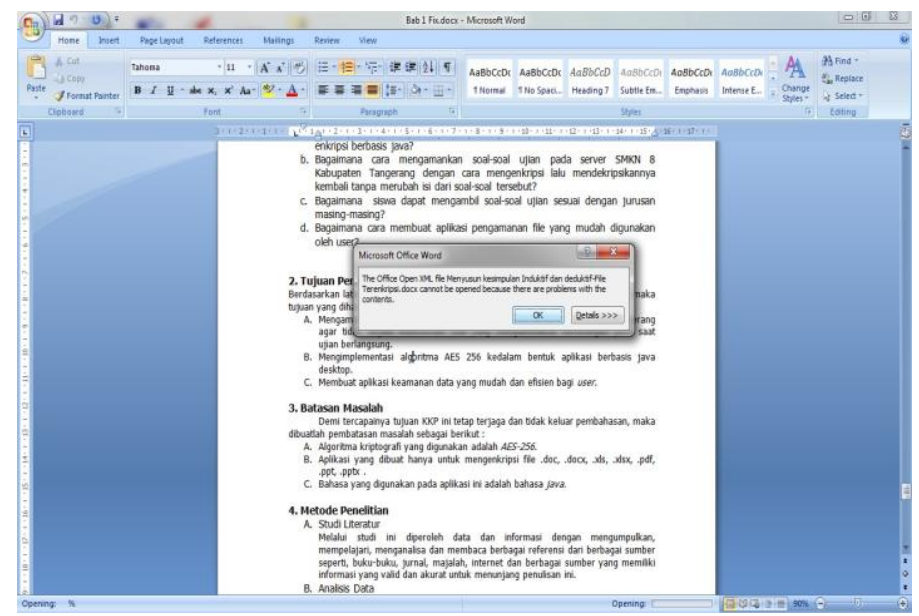

Gambar 10: File berekstensi .doc atau .docx hasil Terenkripsi.

Kedua, file asli (contoh menggunakan file dengan format .xls atau .xlsx) yang akan dienkripsi. File tersebut dapat dilihat pada gambar 11.

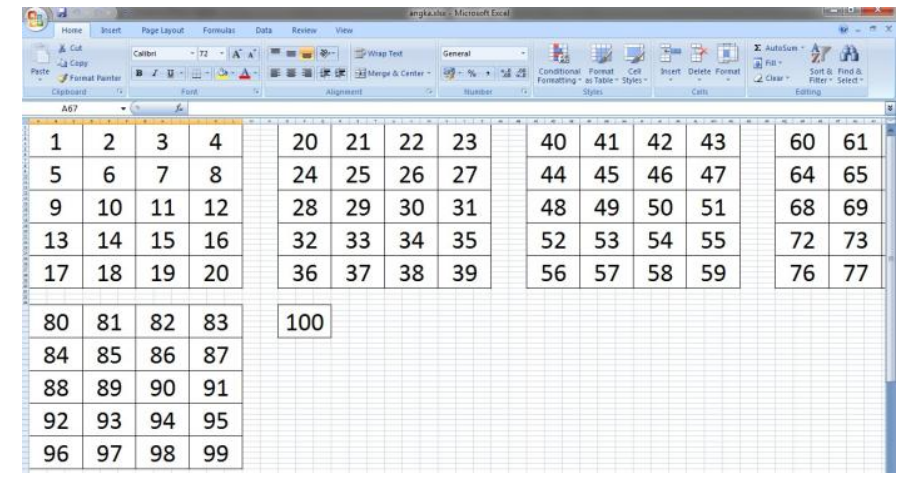

Gambar 11: File berekstensi .xls atau .xlsx Asli 
Apabila file tersebut sudah terenkripsi akan tetap bisa dibuka namun isinya sudah teracak sehingga tidak bisa dibaca. Hasil enkripsi file tersebut dapat dilihat pada gambar 12.

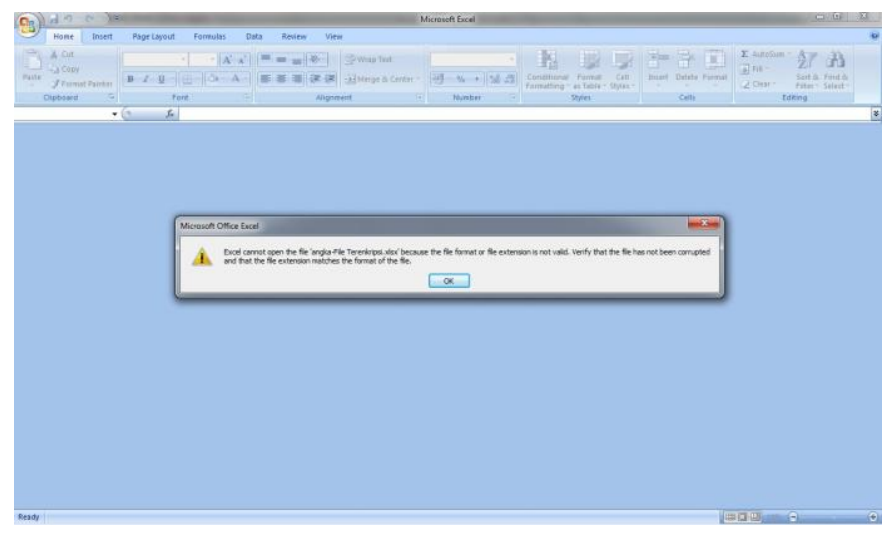

Gambar 12: File berekstensi .xls atau .xlsx hasil Terenkripsi

Ketiga,file asli (contoh menggunakan file dengan format .pdf) yang akan dienkripsi. File tersebut dapat dilihat pada gambar 13.

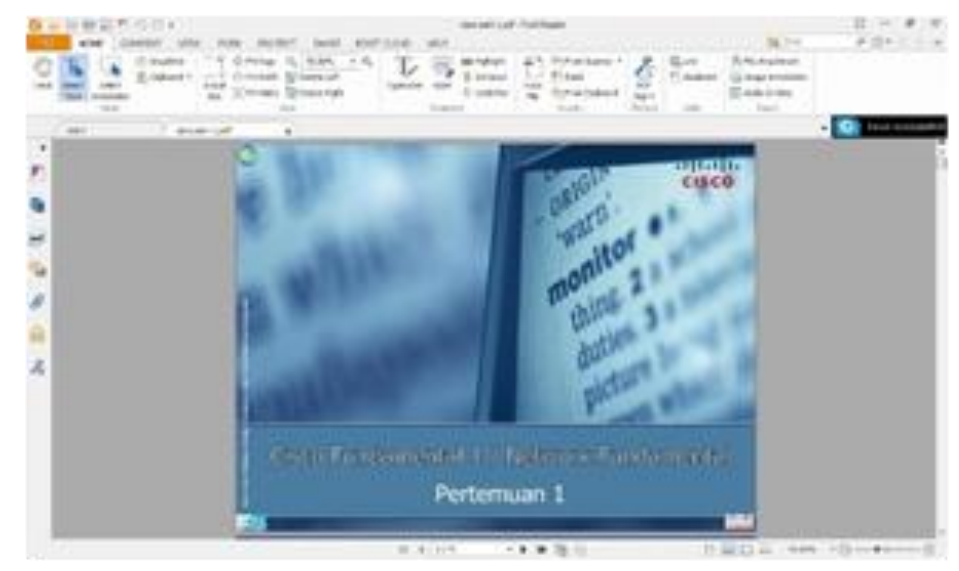

Gambar 13: File berekstensi .pdf Asli

Apabila file tersebut sudah terenkripsi akan tetap bisa dibuka namun isinya sudah teracak sehingga tidak bisa dibaca. Hasil enkripsi file tersebut dapat dilihat pada gambar 14.

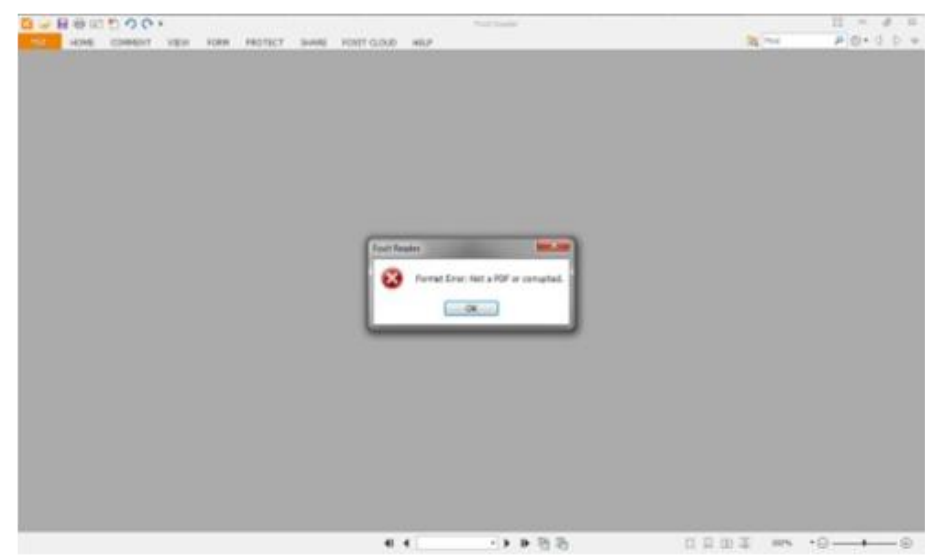

Gambar 14: File berekstensi .pdf hasil Terenkripsi 
Keempat, file asli (contoh menggunakan file dengan format .jpg atau .jpeg) yang akan dienkripsi. File tersebut dapat dilihat pada gambar 15.

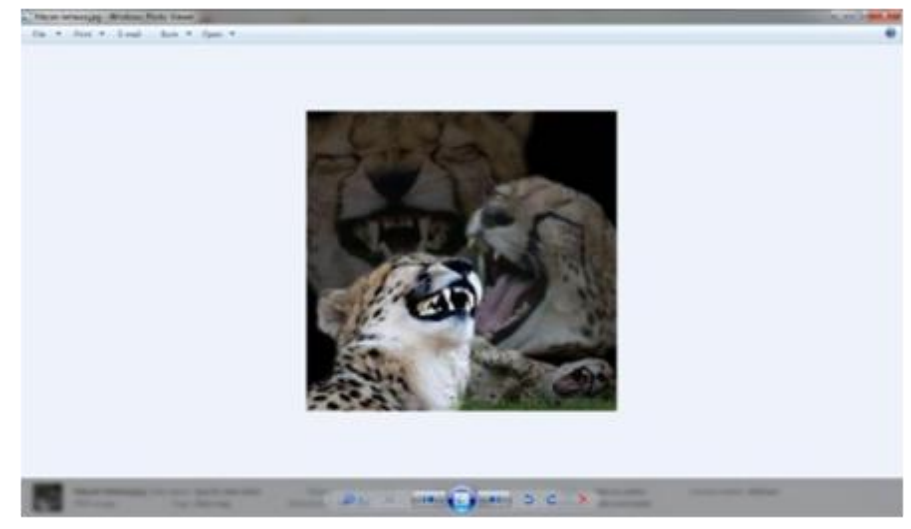

Gambar 15: File berekstensi .jpg atau .jpeg Asli

Apabila file tersebut sudah terenkripsi akan tetap bisa dibuka namun isinya sudah teracak sehingga tidak bisa dibaca. Hasil enkripsi file tersebut dapat dilihat pada gambar 16.

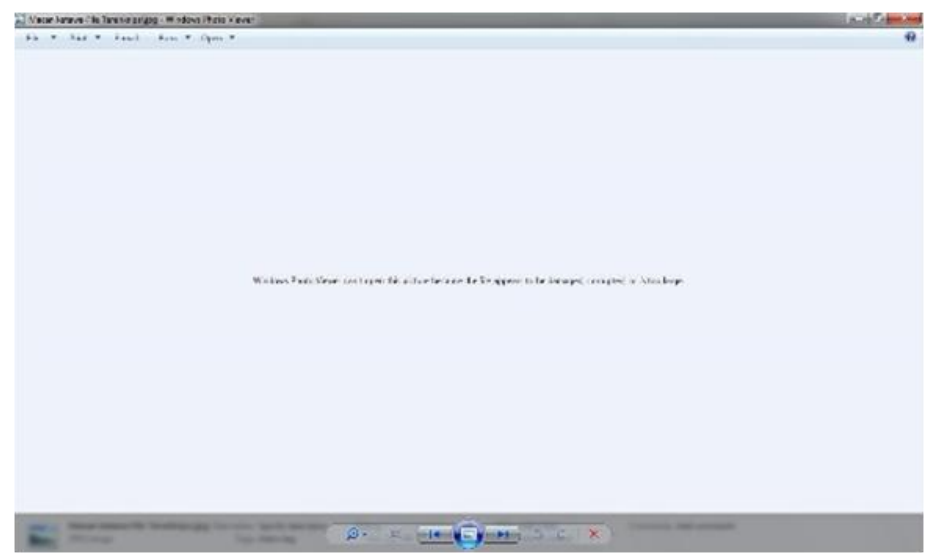

Gambar 16: File berekstensi .jpg atau .jpeg hasil Terenkripsi

Tabel 1: Tabel perbandingan file dokumen asli dan file dokumen hasil enkripsi

\begin{tabular}{|c|l|l|l|l|l|}
\hline No & Nama File & Kunci & Nama File Enkripsi & $\begin{array}{l}\text { Ukuran } \\
\text { File } \\
\text { Asli } \\
(\mathrm{kB})\end{array}$ & $\begin{array}{l}\text { Ukuran } \\
\text { File } \\
\text { Enkrips } \\
\text { i (Kb) }\end{array}$ \\
\hline 1 & $\begin{array}{l}\text { Menyusun } \\
\text { kesimpulan } \\
\text { Induktif dan } \\
\text { deduktif.docx }\end{array}$ & $\begin{array}{l}3456 \text { rewq098 } \\
6-4567- \\
12341 \mathrm{kjh}\end{array}$ & $\begin{array}{l}\text { Menyusun kesimpulan } \\
\text { Induktif dan deduktif-File } \\
\text { Terenkripsi.docx }\end{array}$ & 14 & 14 \\
\hline 2 & Angka.xlsx & $\begin{array}{l}1234-\text {-qwer- } \\
5678-\text {-zxcy }\end{array}$ & $\begin{array}{l}\text { Angka-File } \\
\text { Terenkripsi.xlsx }\end{array}$ & 26 & 26 \\
\hline 3 & cisco pert 1.pdf & $\begin{array}{l}\text { mnbv-kjhg- } \\
\text { iuyt-rewq- } \\
4321-\text {-zxcv }\end{array}$ & $\begin{array}{l}\text { cisco pert 1-File } \\
\text { Terenkripsi.pdf }\end{array}$ & 4.005 & 4.005 \\
\hline 4 & Macan.jpg & $\begin{array}{l}\text { plmn-rewq- } \\
7654-3456\end{array}$ & $\begin{array}{l}\text { Macan-File } \\
\text { Terenkripsi.jpg }\end{array}$ & 29 & 29 \\
\hline
\end{tabular}




\section{KESIMPULAN DAN SARAN}

Adapun kesimpulan dan saran yang didapatkan dari hasil penelitian ini yaitu:

\subsection{Kesimpulan}

Berdasarkan permasalahan dan aplikasi yang telah dibuat, maka dapat ditarik kesimpulan antara lain adalah aplikasi ini sangat mudah untuk dimengerti dan digunakan oleh pengguna serta dapat membantu mengamankan data atau informasi yang sebelumnya dapat dilihat oleh umum atau orang lain. Aplikasi enkripsi ini memiliki tingkat kesulitan enkripsi yaitu 32bit.

\subsection{Saran}

Enkripsi dengan algoritma AES ini masih memiliki beberapa keterbatasan, untuk itu penulis menyarankan untuk mengembangkan aplikasi ini secara berkelanjutan diantaranya membuat aplikasi ini agar dapat mengenkripsi dan mendekripsi data dengan format avi, .mkv,.mp3 dan lain sebagainya secara maksimal, serta dapat mengenkripsi dengan ukuran data yang lebih besar dengan kunci enkripsi yang lebih banyak demi keamanan data tersebut sehingga para pengguna dapat menggunakan aplikasi ini secara optimal.

\section{Daftar Pustaka}

Jurnal

[1] Yuniati, Voni, dkk. (2009). Enkripsi dan dekripsi dengan algoritma aes 256 untuk semua jenis file, Jurnal Informatika, Volume 5 Nomor 1.

[2] Mariana, dkk. (2010). Algoritma XTS-AES Untuk Enkripsi dan Dekripsi Text SMS Berbasis JAVA ME, Jurnal Teknik Informatika STMIK GI MDP.

[3] Angga, Christian. (2011). Perbandingan Super-Enkripsi Berulang vs Vigenere Chiper Kunci Berlapis Metode Triple DES. Sekolah Teknik Elektro Dan Informatika, Bandung

[4] Santoso, Imam Kartika \& Robert Habibi. (2014). Kriptografi Pada Aplikasi Komunikasi Data dengan Algoritma AES 256, Jurnal Ilmu Komputer (SNIK 2014), Semarang.

[5] Noni Endriani, (2014). Implementasi Algoritma AES pada Aplikasi SMS Berbasis Android, Yogyakarta.

[6] Muhammad Humam, (2014). Peningkatan Keamanan Algoritma DES Pada Aplikasi Enkripsi SMS Android Menggunakan Algoritma AES 256 Bit, Universitas Dian Nuswantoro.

[7] Nagesh Kumar, Jawahar Thakur, Arvind Kalia, (2011). Performance Analysis of Symmetric Key Cryptography Algorithms: DES, AES and Blowfish, Journal Anu Books. 